\title{
Uma discussão acerca do papel da aprendizagem organizacional na formação de competências
}

\author{
Marlene Aparecida da Silva Gonçalves Zangiski \\ Mestre em engenharia de produção e sistemas. Professora da \\ Pontifícia Universidade Católica do Paraná (PUCPR), Curitiba, \\ PR, Brasil. \\ E-mail: marlene.zangiski@gmail.com
}

\section{Edson Pinheiro de Lima}

Pós-doutorado em engenharia de produção pela Universidade de Warwick no Reino Unido. Inglaterra. Professor do Programa de Pós-Graduação em Engenharia de Produção e Sistemas da Pontifícia Universidade Católica do Paraná (PUCPR), Curitiba, PR, Brasil.

E-mail: e.pinheiro@pucpr.br

\section{Sérgio Eduardo Gouvêa da Costa}

Pós-Doutorado no Edward P. Fitts Department of Industrial and Systems Engineering da North Carolina State University (EUA). Professor do Programa de Pós-Graduação em Engenharia de Produção e Sistemas da Pontifícia Universidade Católica do Paraná (PUCPR), Curitiba, PR, Brasil.

E-mail:s.gouvea@pucpr.br

\section{Resumo \\ O dinamismo do novo cenário socioeconômico, definido pelo desenvolvimento tecnológico, está provocando a transição de um modelo fundamentado na eficiência individual para outro, cujas bases se estabelecem em medidas da eficiência coletiva. Neste contexto, a aprendizagem organizacional figura como um processo que medeia a geração de conhecimento, de habilidades e de competências para as organizações. Este trabalho fundamenta-se na argumentação de que o conhecimento é o recurso mais importante para a competitividade empresarial, e de que as teorias sobre aprendizagem organizacional contribuem para a sua gênese. A aprendizagem organizacional interage com o conhecimento através de construções teóricas como competências e capacitações, que são definidas no nível organizacional. O objetivo deste trabalho é estudar as relações existentes entre os processos de aprendizagem organizacional e a formação e desenvolvimento de competências organizacionais, no âmbito da gestão de operações. Tais relações foram consolidadas na forma de um framework teórico-conceitual. A pesquisa utilizou abordagem qualitativa, cuja estratégia fundamentou-se em informações obtidas junto a especialistas (profissionais e acadêmicos) e em projeto de implantação de um modelo corporativo para a gestão estratégica de conhecimento. O resultado é o refinamento e teste de um framework que define as relações entre o processo de aprendizagem organizacional e a formação e desenvolvimento de competências que se estabelecem nesse nível. Observa-se que, no contexto da gestão estratégica de operações, a aprendizagem estabelece o processo através do qual se mobilizam recursos. No entanto, esta mobilização é mediada pelas competências organizacionais.}

\section{Palavras-chave}

Aprendizagem organizacional. Competências organizacionais. Gestão do conhecimento e gestão estratégica de operações.

\section{A discussion about the role of organizational learning in the formation of compentencies}

\begin{abstract}
The dynamics of the new socioeconomic scenario, as defined by the technological development, has been causing transition from a model based on individual efficiency to another based on collective efficiency. In this context, organization learning is displayed as a process which furnishes generation of knowledge, capabilities and competencies for the organizations. This paper is based on arguments that knowledge is the most important resource for the entrepreneurial competitiveness, and that the theories about organizational learning contribute to its origin. Organizational learning interacts with knowledge through theoretical constructions as for instance competencies and training, which are defined on an organizational level. The objective of this paper is to study the relations existing between the processes of organizational learning and formation of development of organizational competencies, in the context of management of operations. These relations are consolidated by a theoretical conceptual framework. A qualitative approach was used for research based on information obtained from experts and on the utilization of information from a project of development and implantation of a corporative model for strategic knowledge management. The main conclusion of this paper is the refinement and application of a framework which defines the relations between the process of organizational learning and the formation and development of competencies which are established on the organizational level. In the context created by the strategic management of operations, learning establishes the process by which resources are mobilized. This mobilization, however, is intervened by organizational competencies.
\end{abstract}

\section{Keywords}

Organizational learning. Organizational competencies. Knowledge management. Strategic management of operations. 


\section{INTRODUÇÃO}

A revolução da informação possibilitou a comunicação e transmissão de informações e dados em tempo real entre pessoas e empresas geograficamente distantes (LEE e HONG, 2002). Estas transformações estruturais permitiram a globalização financeira, comercial e produtiva, aumentando o número de competidores e intensificando a competição internacional. (CHOI et al., 2006; SILVA, 2002).

A emergência de um novo contexto, marcado pela dinâmica de mudanças rápidas, profundas e irreversíveis nos mercados, e pela complexidade e a incerteza, nos ambientes interno e externo das organizações (CHOI et al., 2006; SILVA, 2002), originou também novos requisitos para a competitividade empresarial. O potencial poder econômico e de produção de uma organização está centrado em suas capacidades intelectuais, e não mais em seus ativos tangíveis (YEO, 2003).

Fernandes et al. (2005) destacam a diminuição no ciclo de vida dos produtos e a transformação dos processos produtivos, como fatores que requerem das empresas novas formas de aprendizado, nas quais o 'conhecimento' assume um papel de renovação, ao possibilitar a inovação nos produtos e processos organizacionais e de gestão.

Jung et al. (2007) argumentam que em função das mudanças cada vez mais aceleradas dos requisitos de mercado, a criação de conhecimento nas organizações não é apenas uma questão de competitividade no longo prazo, mas também de sobrevivência das empresas no mercado.

As transformações ocorridas reforçam a argumentação de Drucker (1993), de que o conhecimento é "o único recurso" significativo atualmente e o trabalhador do conhecimento é o maior ativo das organizações, e nesta definição inclui-se, por exemplo, um profissional que sabe alocar o conhecimento para uso produtivo, assim como o 'capitalista' sabia alocar o capital para uso produtivo.
O desenvolvimento de uma estratégia competitiva baseada na gestão do conhecimento implica uma revisão dos padrões culturais da organização, de modo que haja ênfase na aprendizagem contínua e em compreender a dinâmica da relação entre os processos de aprendizagem organizacional e a formação e o desenvolvimento de competências organizacionais têm sido uma das questões chave no desenvolvimento da estratégia de negócios (HALAWI et al. 2006; DAWSON, 2000).

A aprendizagem organizacional figura como um processo chave que atrai atenção crescente dos pesquisadores e engloba pessoas, suas relações, o compartilhamento de informações, a experimentação, a disseminação do conhecimento e vários outros elementos inerentes ao processo de interação existente nas organizações. Deve-se também observar que o conhecimento criado é mobilizado através das competências e estas exercem papel fundamental na integração estratégica (BROWN e BLACKMON, 2005).

Este artigo apresenta o desenvolvimento e teste de um framework teórico-conceitual para analisar e representar a relação entre os processos de aprendizagem organizacional e de formação e desenvolvimento de competências organizacionais, estabelecidos no âmbito da gestão de operações.

A definição do problema de pesquisa está apoiada na relevância do papel das competências organizacionais para a mobilização dos recursos da empresa e, consequentemente, para a geração de resultados, ou seja, atingir determinados níveis de desempenho. Não há um conjunto de procedimentos e práticas padronizados para a aprendizagem organizacional e a formação de competências organizacionais. Estes procedimentos e práticas variam em função de características internas da organização e do ambiente no qual ela está inserida. 


\section{REVISÃO DE LITERATURA E CONSTRUÇÃO DO FRAMEWORK}

Embora o conhecimento seja entendido inicialmente como um recurso humano, decorrente do treinamento e experiência das pessoas, ele passa a ser abordado, de acordo com a visão baseada em recursos, como um recurso estratégico da organização, mobilizado em processos através de uma relação mediada por competências (PAIVA et al., 2008; MERALI, 2000).

A compreensão da ligação entre os recursos da organização e a sustentabilidade da vantagem competitiva, é entendida como fator de grande importância para a estratégia; os recursos são categorizados em físicos, humanos e organizacionais, sendo o conhecimento parte integrante dos recursos humanos (BARNEY, 1991).

As relações entre os indivíduos e entre os grupos em uma organização permitem o desenvolvimento coletivo, coerente e sinérgico do conhecimento organizacional, muito além da soma das contribuições individuais. (TOMAÉL et al., 2005; VASCONCELOS, 2001).

\section{Processo de aprendizagem organizacional}

O processo de aprendizagem organizacional exige novas formas de pensar e mudança de comportamento, pois ocorre através de mecanismos de processamento de informações, onde as novas ideias, originadas dentro ou fora da organização, são essenciais. (GARVIN, 1993).

Para Garvin (1993), o processo de aprendizagem organizacional decorre de habilidades em cinco atividades principais, conforme apresenta a figura 1.

Segundo a abordagem de Chen (2005), a aprendizagem organizacional é um sistema composto por nove subsistemas de aprendizagem organizacional, cujas inter-relações estão representadas na figura 2.

Nos sistemas de aprendizagem organizacional, a memória organizacional figura como o recurso mais importante, permitindo que o processo de aprendizagem seja contínuo e ininterrupto.

Argyris (1996) propõe a existência de dois tipos de aprendizagem: single-loop e double-loop, que são apresentadas no quadro 1.

\section{FIGURA 1}

\section{Habilidades para o processo de aprendizagem organizacional}

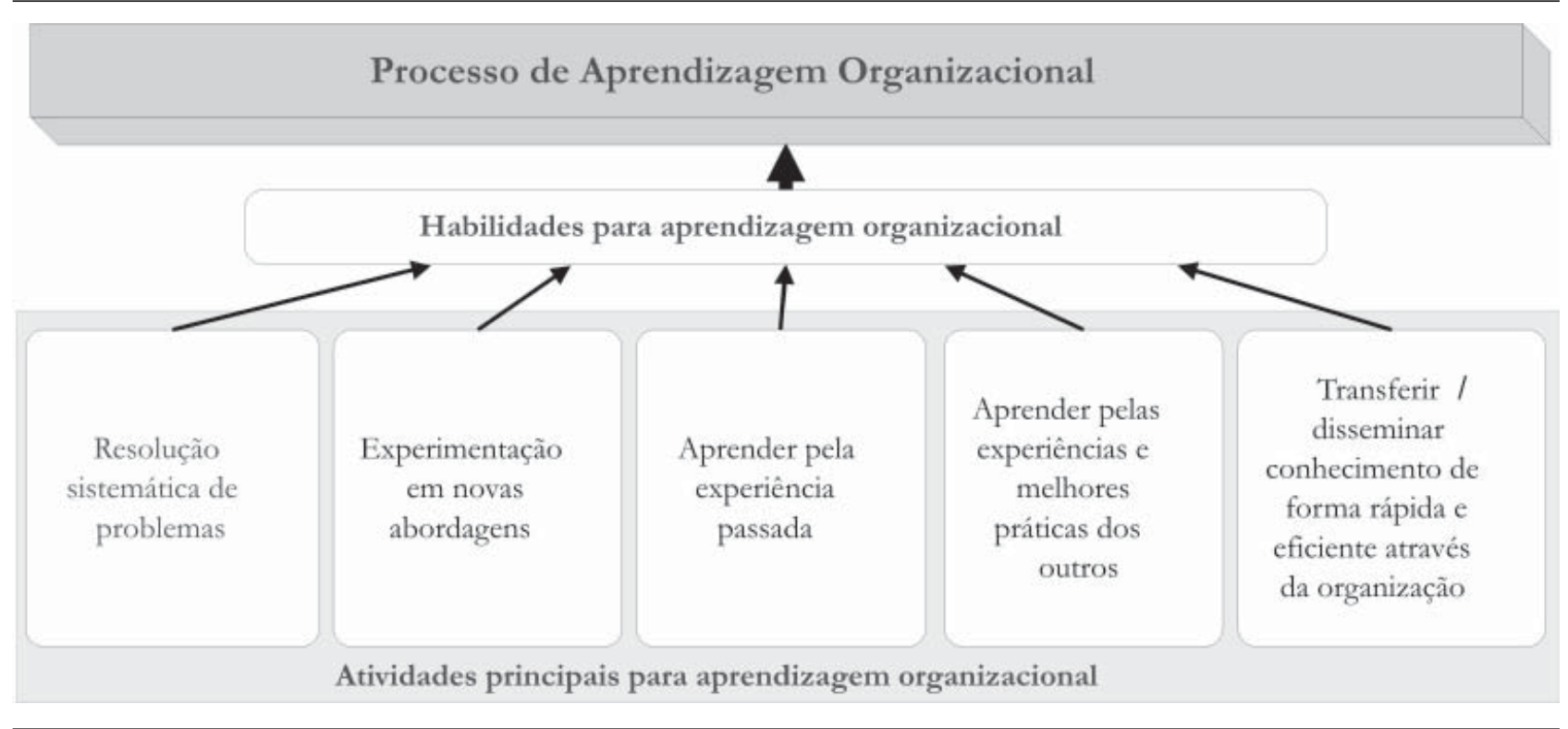

Fonte: Elaborado pelos autores 
FIGURA 2

Subsistemas de aprendizagem organizacional

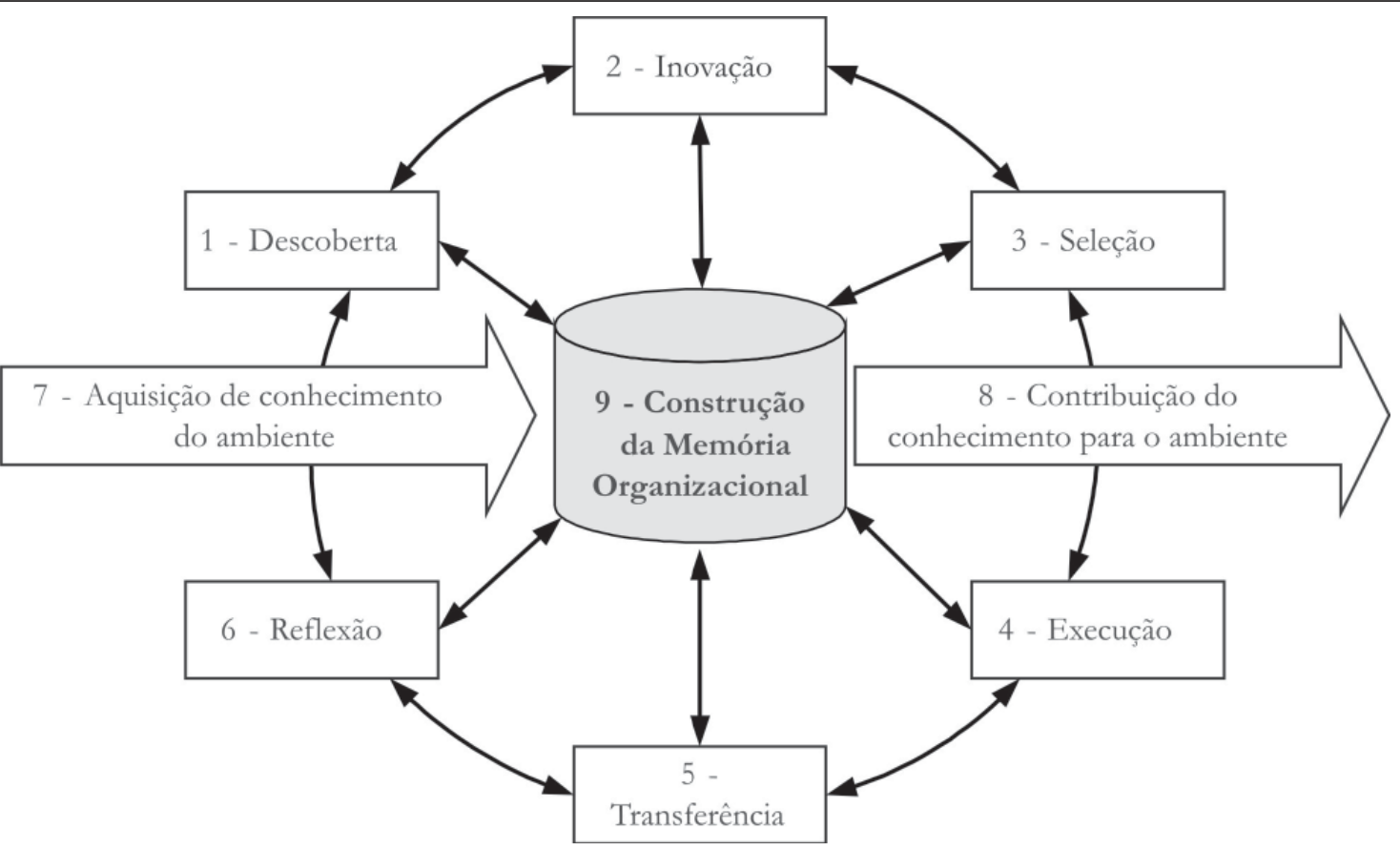

Fonte: Adaptado de Chen (2005)

QUADRO 1

Tipos de aprendizagem Double-Loop e Single-Loop e características

\begin{tabular}{|c|c|c|}
\hline & Single-Loop & Double-Loop \\
\hline $\begin{array}{l}\text { Valores } \\
\text { preponderantes } \\
\text { dos adeptos }\end{array}$ & $\begin{array}{l}\text { - Ter controle unilateral das } \\
\text { situações } \\
\text { - Esforçar-se para ganhar } \\
\text { - Suprimir os sentimentos } \\
\text { negativos próprios e alheios } \\
\text { - Ser o mais racional possível }\end{array}$ & $\begin{array}{l}\text { - Utilizar informações válidas } \\
\text { - Dar às pessoas o direito de optar livremente e com } \\
\text { informação } \\
\text { - Assumir responsabilidade pessoal no monitoramento } \\
\text { da eficácia }\end{array}$ \\
\hline Ações & $\begin{array}{l}\text { - Defender sua posição } \\
\text { - Avaliar os pensamentos e as } \\
\text { ações dos outros (e seus } \\
\text { pensamentos e ações) } \\
\text { - Atribuir causas ao que quer que } \\
\text { esteja tentando entender }\end{array}$ & $\begin{array}{l}\text { - Criar situações ou ambientes em que os participantes } \\
\text { possam ser originais e sintam alto nível de gratificação } \\
\text { pessoal (sucesso psicológico, afirmação, sensação de ser } \\
\text { essencial) } \\
\text { - Proteger-se passa a ser um empreendimento conjunto e } \\
\text { orientado para o crescimento (tenta-se reduzir a } \\
\text { cegueira em relação à própria inconsistência e } \\
\text { incongruência) } \\
\text { - Proteger os outros é algo feito em paralelo }\end{array}$ \\
\hline $\begin{array}{l}\text { Resultados de } \\
\text { aprendizado }\end{array}$ & $\begin{array}{l}\text { - Os resultados são limitados ou } \\
\text { inibidos } \\
\text { - Há conseqüências que } \\
\text { encorajam os mal-entendidos } \\
\text { Surgem processos de erro auto- } \\
\text { alimentáveis }\end{array}$ & $\begin{array}{l}\text { - O aprendizado é facilitado } \\
\text { - Há uma redução gradual e constante dos mecanismos } \\
\text { de defesa organizacionais }\end{array}$ \\
\hline
\end{tabular}

Fonte: Adaptado de Argyris (1993).

Ci. Inf., Brasília, DF, v. 38, n. 3, p.142-159, set./dez., 2009 
Para Ayas (1997), a construção da capacidade de aprendizagem implica a criação de uma infraestrutura para manter a aprendizagem em todos os níveis, permitindo que se crie uma capacidade de produzir conhecimento, bem como um contexto para compartilhar o conhecimento.

Algumas das principais abordagens acerca da aprendizagem organizacional são apresentadas no quadro 2.

A aprendizagem organizacional é abordada sob diversos focos, com pontos convergentes relacionados à ideia da aprendizagem resultante da experiência individual, das trocas de experiência e inter-relações entre as pessoas e os grupos na organização, assim como a criação de ambientes organizacionais favoráveis às práticas de aprendizagem.

\section{Competências e capacitações organizacionais}

Para Sanchez (2004) as competências podem ser definidas através de cinco modos de 'ação': flexibilidade cognitiva para conceber lógicas de estratégias alternativas; flexibilidade cognitiva para conceber processos de gestão alternativos; flexibilidade de coordenação para identificar,

\section{QUADRO 2}

\section{Síntese das teorias sobre a aprendizagem organizacional}

\begin{tabular}{|c|c|}
\hline Autor & Considerações e conclusões \\
\hline $\begin{array}{c}\text { Garvin } \\
(1993)\end{array}$ & $\begin{array}{l}\text { Aprendizagem como um processo de aquisição de conhecimento, através de mecanismos de } \\
\text { processamento de informações, onde as novas idéias são essenciais e podem originar-se dentro ou } \\
\text { fora da organização, decorrentes de experiência, experimentação, lições aprend idas, melhores } \\
\text { práticas e disseminação rápida e eficiente do conhecimento na organização. }\end{array}$ \\
\hline $\begin{array}{l}\text { Argyris } \\
(1996)\end{array}$ & $\begin{array}{l}\text { Aprendizagem Single-Loop, que permite a manutenção do conhecimento. } \\
\text { Aprendizagem Double-Loop, que permite a criação de conhecimento. }\end{array}$ \\
\hline $\begin{array}{l}\text { Ayas } \\
(1997)\end{array}$ & $\begin{array}{l}\text { Capacidade de aprendizagem relacionada à criação de infra-estrutura para suportar os processos de } \\
\text { aprendizagem, e à diversidade de conhecimentos, habilidades, valores e insigts. }\end{array}$ \\
\hline $\begin{array}{l}\text { Nonaka e } \\
\text { Takeuchi } \\
\text { (1997) }\end{array}$ & $\begin{array}{l}\text { A Criação de conhecimento essencialmente baseada em elem entos flexíveis e qualitativos. A } \\
\text { aprendizagem ocorre mais em função da experiência diária e utilização da linguagem metafórica que } \\
\text { de programas de treinamentos formais. }\end{array}$ \\
\hline $\begin{array}{l}\text { Dixon, } \\
(1999)\end{array}$ & $\begin{array}{l}\text { Uso intencional do processo de aprendizagem nos níveis individuais, de grupos e de sistemas como } \\
\text { forma de transformação organizacional. }\end{array}$ \\
\hline $\begin{array}{l}\text { Senge } \\
(2000)\end{array}$ & $\begin{array}{l}\text { Aprendizagem baseada nas cinco disciplinas da aprendizagem (Domínio pessoal, Modelos mentais, } \\
\text { Visão compartilhada, Aprendizagem em equipe e Pensamento sistêmico) }\end{array}$ \\
\hline $\begin{array}{l}\text { Cecez- } \\
\text { Kecmanov } \\
(2004)\end{array}$ & $\begin{array}{l}\text { Aprendizagem focada no desenvolvimento de habilidades técnicas e expertise, entendimento do } \\
\text { negócio e da empresa, habilidades pessoais de comunicação, competência comunicativa dos } \\
\text { indivíduos, e cultura que favoreça o debate aberto e os processos de interação social. }\end{array}$ \\
\hline $\begin{array}{l}\text { Chen } \\
(2005)\end{array}$ & $\begin{array}{l}\text { Memória organizacional como o recurso mais importante para a aprendizagem } \\
\text { Propósito da aprendizagem organizacional focado na adaptação da organização às mudanças dos } \\
\text { ambientes interno e externo. } \\
\text { A aprendizagem é um processo contínuo e ininterrupto. }\end{array}$ \\
\hline $\begin{array}{l}\text { Fliaster et } \\
\text { al. (2008) }\end{array}$ & $\begin{array}{l}\text { Aprendizagem baseada nas redes sociais } \\
\text { As redes sociais na empresa podem auxiliar a identificar ou reformular problemas, validar idéias e o } \\
\text { curso de uma ação, possibilitar a perspectiva crítica, evidenciar oportunidades e permitir que os } \\
\text { problemas sejam mais bem distribuídos pela divisão do trabalho. }\end{array}$ \\
\hline
\end{tabular}


configurar e alocar recursos; flexibilidade de recursos para serem usados em diferentes alternativas; flexibilidade de operação no uso de habilidades individuais e capacitações nos recursos disponíveis.

De acordo com Zehir et al. (2006), capacitação é um conceito mais amplo que competência, incluindo além de competências, estratégia e a ligação entre recursos e habilidades. As habilidades e competências são mostradas na área técnica individual e nas questões sociais, respectivamente. As capacitações referem-se a ambas, na área técnica e nas questões sociais de uma organização.

Mills et al. (2003), ao tratar das competências e capacitações, argumentam que o termo competência é comumente usado no contexto estratégico, como um elemento que pode ser usado para alcançar a vantagem competitiva.

Na visão Hamel e Prahalad (1990), a competência organizacional define a lógica para mobilização de recursos, logo, os resultados de desempenho são função do nível de competência.

O quadro 3 apresenta a categorização das competências organizacionais segundo Mills et al. (2002).

Vários autores abordam a relação aprendizagem versus formação de competências. Destacam-se: Drejer $(2000,2001)$ na integração entre competências individuais e organizacionais (mediadas pelo processo de aprendizagem); Sanchez (2004) na busca de uma arquitetura lógica para classificar e explicar a formação de competências; Rose et al. (2007) e Murray e Donegan (2003) no estabelecimento das relações de causa e efeito; Spanos e Prastacos (2004) no estudo dos mecanismos de socialização; Lee et al. (2005) e Hunter (2002) na análise do resultado da aprendizagem e seu efeito na formação de capacitações e no desempenho; Turner e Keegan (2001) na análise da governança e suas relações com aprendizagem organizacional e desenvolvimento de competências; Chen e Wu (2007), Macpherson et al. (2003) e Hoogervorst et al. (2002) na definição das competências como resultado do processo de aprendizagem; Miranda (2006), definindo competências a partir das necessidades.

Destaca-se que há uma clara relação entre o processo de aprendizagem organizacional e a formação e desenvolvimento de competências, sendo este último definido como seu resultado.

Para que a organização saiba que competências desenvolver, é necessário que tenha conhecimento de sua estrutura interna, do ambiente externo e de sua interação com este ambiente. $\mathrm{O}$ conceito de 'valor' a ser criado ou a orientação ao cliente podem constituir direcionadores na formação de competências (YANG et al., 2006; BERGHMAN et al., 2006; WANG e LO, 2003; BOOG, 1991).

\section{QUADRO 3}

\section{Categorias de competências}

\begin{tabular}{l|l}
\hline Categorias de competência & \multicolumn{1}{c}{ Descrição } \\
\hline Competências essenciais & $\begin{array}{l}\text { Competências e atividades mais elevadas, no nível corporativo, que são chave } \\
\text { para a sobrevivência da empresas e centrais para a estratégia. }\end{array}$ \\
\hline Competências distintivas & $\begin{array}{l}\text { Competências e atividades que os clientes reconhecem como diferenciadores } \\
\text { de seus concorrentes e que provêem vantagens competitivas. }\end{array}$ \\
\hline $\begin{array}{l}\text { Competências organizacionais } \\
\text { ou das unidades de negócios }\end{array}$ & $\begin{array}{l}\text { Competências e atividades chave esperadas de cada unidade de negócios da } \\
\text { empresa, geralmente em pequeno número, de três a seis. }\end{array}$ \\
\hline Competências de suporte & Atividade valiosa para apoiar um leque de outras atividades. \\
\hline $\begin{array}{l}\text { Capacidades ou capacitações } \\
\text { dinâmicas }\end{array}$ & $\begin{array}{l}\text { Capacidade da empresa em adaptar suas competências com o tempo. } \\
\text { É diretamente relacionada aos recursos importantes para mudança. }\end{array}$ \\
\hline
\end{tabular}

Fonte: Mills et al. (2002). 


\section{Gestão estratégica de operações}

Slack (2003) destaca a importância das operações e do gerenciamento de processos na organização. A área de operações tem grande impacto nos custos e receitas da empresa, e busca a melhoria dos produtos e serviços e redução de custos, principalmente através dos processos.

O modelo de produção enfatizado no desenvolvimento deste trabalho é o da manufatura dinâmica, que segundo De Toni e Tonchia (2002), é baseada na teoria da competência e se fundamenta na criação de capacitações operacionais futuramente importantes.
A figura 3 representa como a visão da estratégia de manufatura se integra aos modelos da organização industrial e da teoria da competência.

A estratégia de manufatura no modelo da teoria da competência é focada no gerenciamento dos recursos e competências de produção, que são abordados como fonte potencial de vantagem competitiva derivada da produção. Nesta perspectiva, a estratégia de operações (de manufatura, de serviços ou de produção) pode estabelecer um contexto para estudar a relação entre aprendizagem e competências (PAIVA et al., 2008).

\section{FIGURA 3}

Integração da visão da estratégia de manufatura à organização industrial e Teoria da Competência

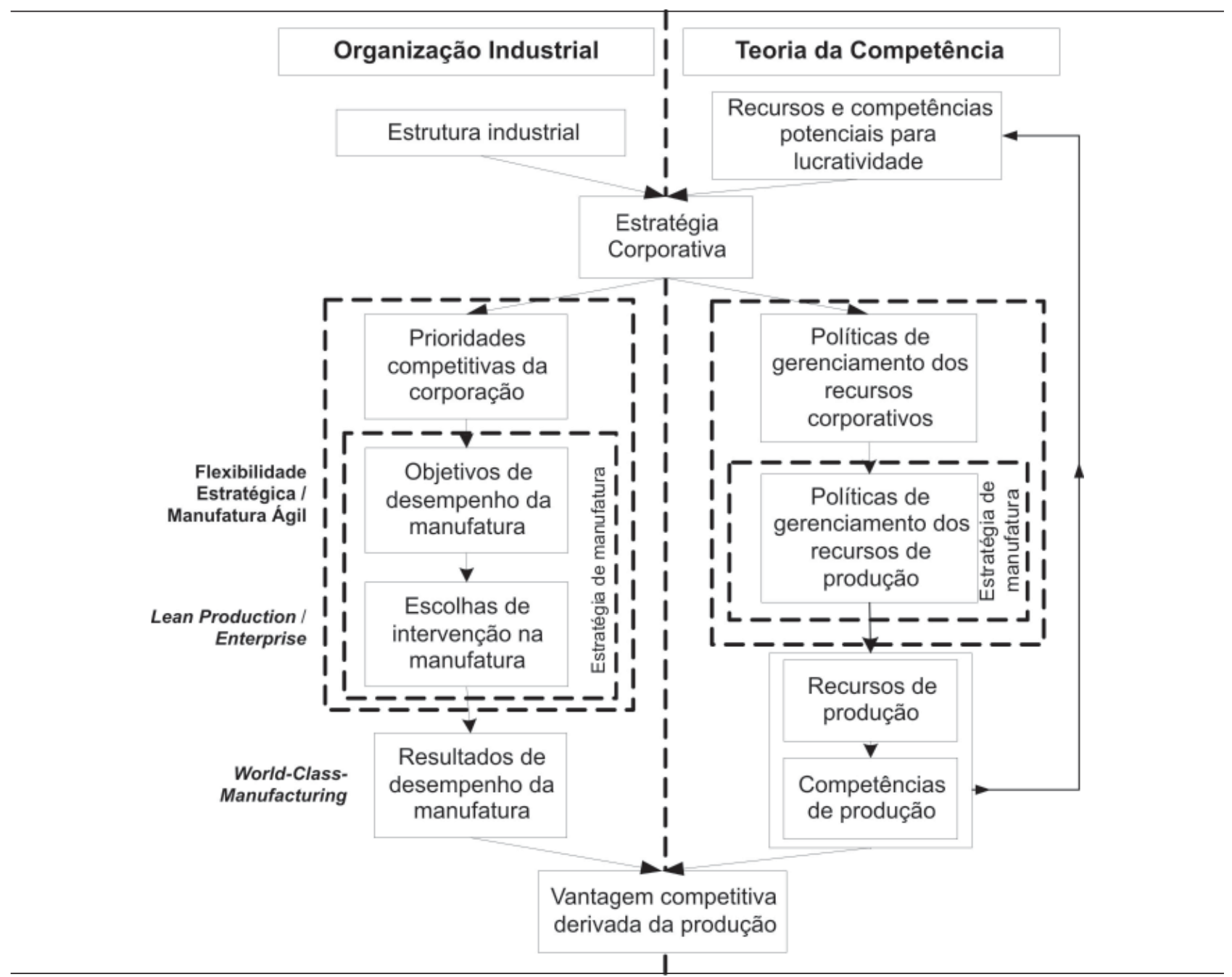

Fonte: adaptado de De Toni e Tonchia (2002) 
As competências organizacionais ligadas à gestão de operações, segundo Lewis (2003), têm como objetivo o alinhamento das operações com o mercado, visando a transformação de processos, combinação de recursos e processos operacionais e competitividade e performance dos resultados com o uso otimizado dos recursos.

No âmbito da gestão de operações, a formação e a realização da visão de manufatura, segundo Johansen e Riis (2003), figuram como um processo que traça uma ponte entre missão, objetivos e estratégia da organização, através do qual se desenvolve a aprendizagem organizacional. Paiva et al. (2008) também propõem um modelo de estratégia de operações em que os recursos e capacitações são desenvolvidos cumulativamente, gerando aprendizagem e conhecimento.

O objetivo da visão de manufatura, de acordo com Maslen e Platts (1997), é permitir o refinamento do processo de criação da estratégia de manufatura e adaptação à visão de manufatura dinâmica.

Desenvolver a visão de manufatura facilita a criação da estratégia dentro do paradigma da manufatura dinâmica, mediante a explicitação das capacidades de exploração dos fatores que exercem influência sobre o potencial competitivo, e de direcionamento para mudança, com alinhamento aos requisitos de mercado (MASLEN e PLAT'TS, 1997).

A visão de manufatura é a descrição de uma série de capacitações da manufatura direcionadas ao desenvolvimento do negócio, provenientes de um grupo de recursos combinados em forma estrutural, infra-estrutural e de recursos humanos.

O método para criação da visão de manufatura consiste em quatro estágios:

1. Geração de ideias, utilização de brainstorming.

2. Conjunto de ideias, estruturação das ideias do estágio 1.

3. Refinamento de visão, mediante entrevistas e grupos.

4. Visão prioritária, foco para a mudança.

Ci. Inf., Brasília, DF, v. 38, n. 3, p.142-159, set./dez., 2009
Organizações que não tem visão dos competidores podem perder mercado e ter alto custo de recuperação, o que pode ocorrer em função da falta de alinhamento entre as estratégias corporativa e de manufatura (HAYES e WHEELWRIGHT, 1985).

A estratégia da manufatura deve estar integrada na organização como um todo, e precisa envolver também a criação de capacitações e competências organizacionais, que a empresa possa utilizar para competir no futuro (HAYES e PISANO, 1994).

O processo de desenvolvimento da visão de manufatura implica a integração da dimensão tecnológica e da visão gerencial visando à mudança de paradigmas relativos à cultura, processos, qualificação e outros.

A aprendizagem da gestão de operações consiste na análise das operações diárias, reflexão sobre o modo de trabalho, interação e especulação do futuro sem temer o erro. Para isto, o diálogo colaborativo, com a captura de ideias inovativas e conhecimento, constitui o potencial de inovação despertado pela visão de manufatura e cria condições para a aprendizagem do tipo double-loop.

O quadro 4, a seguir, apresenta as questões relacionadas à visão de manufatura.

As características e inter-relações destas questões criam condições para a aprendizagem organizacional através da experimentação, explorando novas ideias; da participação, com o envolvimento das pessoas em todo o processo; e na definição dos princípios, quando promove a interação entre funções.

\section{METODOLOGIA}

A metodologia de pesquisa desenvolvida é de natureza qualitativa, devido às características essencialmente subjetivas e qualitativas dos dados analisados.

O propósito do trabalho é o desenvolvimento de um framework teórico-conceitual que represente as inter-relações do processo de aprendizagem organizacional e de formação de competências organizacionais. 
QUADRO 4

Questões relacionadas ao desenvolvimento da visão de manufatura

\begin{tabular}{|c|c|}
\hline Questão & Características \\
\hline $\begin{array}{l}\text { Modo de trabalbo } \\
\text { experimental }\end{array}$ & $\begin{array}{l}\text { - } \quad \text { Experimentação sem medo de errar na busca de uma situação futura idealizada. } \\
\text { - Suporte de facilitadores para envolver as pessoas ativamente no processo criativo (mix } \\
\text { de seminários e forças-tarefa). } \\
\text { - } \quad \text { Linguagem: utilização de expressões como "Por que não fazer...", "O que aconteceria } \\
\text { se...", "Poderíamos imaginar que...", i maginação e exploração de novas idéias. }\end{array}$ \\
\hline Participação & $\begin{array}{l}\text { - Envolvimento de gerentes e funcionário desde as fases iniciais do processo. } \\
\text { - Envolvimento de toda a organização na apreciação do que é preciso para mu dar, e na } \\
\text { discussão e experimentação de soluções futuras (direção). } \\
\text { - } \quad \text { Comunicação/informação: representação de desafios com todas as funções da } \\
\text { organização. } \\
\text { - E Enfase no potencial das contribuições baseadas nas experiências no trabalho. } \\
\text { - Envolvimento do nível operacional na compreensão das necessidades de mudanças e no } \\
\text { desenvolvimento de soluções criativas. }\end{array}$ \\
\hline
\end{tabular}

Fonte: adaptado de Johansen e Riis (2003)

A análise destas inter-relações foi realizada, em um primeiro momento, no framework construído e refinado resultante da revisão de literatura e das entrevistas com os especialistas, e em seguida, com base na identificação de elementos comuns entre o framework desenvolvido e mapas cognitivos que permitiram organizar as informações coletadas junto ao projeto de GC.

Para a coleta das informações necessárias ao refinamento do framework, foram entrevistados seis especialistas, três da área acadêmica e três da área empresarial, cujas atividades profissionais são ligadas à gestão do conhecimento, sendo que dois são funcionários da organização analisada e estão diretamente envolvidos com o projeto. As entrevistas foram conduzidas no período de julhoagosto de 2007 , e tiveram duração média de uma hora e meia com cada especialista.

O profissional 1 exerce o cargo de gestor em programa de desenvolvimento organizacional, possui mestrado em economia e administração do setor público, está na organização há 18 anos, e é um dos integrantes da empresa ligados à implantação do projeto de Gestão Estratégica do Conhecimento.

O profissional 2 é graduado em engenharia civil, possui especialização na área de administração e exerce o cargo de engenheiro civil há três anos na empresa.

O profissional 3 atua como coordenador de projetos e consultor nas áreas de gestão do conhecimento, competitividade, desenvolvimento industrial, gestão pública, e outras áreas afins. Possui doutorado em engenharia de produção e cerca de 25 anos de experiência profissional atuando nos setores público e privado.

O acadêmico 1 é professor universitário com 10 anos de experiência nas áreas de gestão do conhecimento, aprendizagem organizacional, gestão do capital intelectual, educação corporativa, comunicação empresarial e marketing. É mestre em administração de empresas, está desenvolvendo tese de doutorando na área de gestão do conhecimento.

O acadêmico 2 é doutor em administração de empresas, atua nas linhas de pesquisa de gestão estratégica do conhecimento e de inovação organizacional. Possui experiência profissional de cerca de 30 anos, sendo 20 deles como professor universitário.

O acadêmico 3 possui pós-doutorado na Warwick Business School, Inglaterra, e doutorado em engenharia de produção. Atua há 20 anos como professor universitário, e participa 
de linhas de pesquisa na área de estratégia, tecnologia e organizações, particularmente em projetos relacionados à estratégia de operações, medição de desempenho e gestão estratégica do conhecimento.

Embora trabalhe em parte com a análise de uma amostra relativamente grande de dados secundários, a pesquisa tende para o paradigma fenomenológico, em função da natureza essencialmente qualitativa e subjetiva dos dados (COLLIS e HUSSEY, 2005). Estas características justificam a análise fundamentada em métodos não quantitativos.

Para a fase de teste do framework, foram analisados dados secundários provenientes de um projeto de gestão estratégica do conhecimento; a coleta e a análise dos dados e informações do projeto ocorreram entre fevereiro e julho de 2007, com a aplicação do questionário para 342 funcionários de cinco unidades organizacionais, identificadas pelas siglas DA, DC, DF, DG, DJ e DT.

A massa de dados secundários é composta por 342 questionários, aplicados em seis unidades organizacionais com o objetivo de diagnosticar ações de gestão do conhecimento na empresa.

As 342 respostas foram importadas para uma só planilha em formato Microsoft Excel ${ }^{\circledR}$, onde cada linha corresponde a um questionário e cada coluna corresponde a um campo de resposta do questionário. Da totalidade respondida, 46 foram selecionados para testar o framework após o refinamento, utilizando os seguintes critérios: descarte das respostas incompletas ou inconsistentes; ocultação de colunas correspondentes a campos de resposta não aplicáveis à análise; realização de busca simples por palavras-chave: conhecimento, aprendizagem, competência, informação/informações, processo, operação/operações; descarte das respostas cujas ações identificadas poderiam, potencialmente, não trazer contribuições significativas para aprendizagem organizacional; e descarte de respostas similares.

Ci. Inf., Brasília, DF, v. 38, n. 3, p.142-159, set./dez., 2009
A fase de teste do framework, dado o volume dos dados, exigiu considerável tempo e esforço, no sentido de analisar a massa de dados em sua totalidade, priorizando a identificação de informações relevantes para o atingimento dos objetivos da pesquisa, e a evidenciação das contribuições para a gestão de operações.

Para tanto, usou-se a técnica de mapas cognitivos, que, de acordo com Collins e Hussey (2005), é utilizada para estruturar, analisar e entender o sentido das narrações escritas ou verbais presentes nas respostas. O objetivo dos mapas cognitivos, na fase de teste do framework, é de identificar padrões de aprendizagem.

Os mapas cognitivos foram construídos utilizando o Microsoft Visio ${ }^{\circledR}$ e seguindo os três estágios mencionados por Collins e Hussey (2005):

1. A narrativa do problema é dividida em frases de cerca de 10 palavras que mantêm a linguagem utilizada pela pessoa. Essas frases são tratadas como conceitos distintos que são reconectados para representar a narrativa em formato gráfico, revelando o padrão de raciocínio.

2. Pares de frases podem ser unidos em um só conceito, no qual uma fornece contraste significativo para a outra.

3. As frases distintas são ligadas para formar uma hierarquia de significados objetivos, o que envolve decidir sobre o status de um conceito em relação ao outro, e o significado é mantido por meio do contexto.

A utilização dos mapas cognitivos justifica-se por permitir preservar a integridade e a propriedade original dos dados, evitando-se abreviaturas de frases ou palavras. Durante a elaboração dos mapas cognitivos, foram realizados somente ajustes relativos à grafia, com o intuito de facilitar e tornar claro o entendimento.

Dadas estas características, os mapas cognitivos constituem elementos que podem ser utilizados para testar o framework desenvolvido. 


\section{Refinamento}

O refinamento é desenvolvido via entrevista com especialistas e o teste com os mapas cognitivos do projeto de GC.

O refinamento do framework foi realizado com base nas entrevistas com os especialistas na área de gestão do conhecimento, e permitiu maior detalhamento dos elementos e maior clareza na representação das relações entre esses elementos.

As entrevistas foram conduzidas com base em um roteiro predefinido, de maneira semiestruturada, e permitiram a coleta de dados importantes para o refinamento do framework de referência.

O quadro 5 apresenta uma síntese das contribuições e discussões das entrevistas com os especialistas.

A figura 4, a seguir, representa o framework teóricoconceitual após o processo de refinamento:

Tendo o framework refinado, pode-se testá-lo à luz dos dados obtidos no projeto, cujas informações apresentam-se na forma de mapas cognitivos.

\section{Teste do framework teórico-conceitual}

A organização analisada é uma empresa de propriedade pública prestadora de serviços de geração de energia elétrica.

Este capítulo visa a testar o framework com o objetivo verificar sua usabilidade e a aplicabilidade. O teste foi desenvolvido com base em analogia entre os elementos e inter-relacionamentos presentes no framework e nos mapas cognitivos, com o objetivo de identificar elementos comuns e divergências que permitam aprimorar o framework e desenvolver sugestões e/ou recomendações.

Para possibilitar a identificação, todos os questionários foram numerados sequencialmente de 001 a 342, e os mapas cognitivos foram identificados com duas letras e três números. As duas letras representam a sigla da unidade organizacional da qual o respondente faz parte, e os três números representam a ordem sequencial do questionário. Os mapas cognitivos e os dados brutos estão no idioma de origem em que foram respondidos os questionários.

QUADRO 5

Síntese das contribuições das entrevistas com especialistas

\begin{tabular}{l|l}
\hline Entrevistado & \multicolumn{1}{c}{ Contribuições } \\
\hline Profissional 1 & $\begin{array}{l}\text { Ênfase na codificação e retenção do conhecimento crítico para a organização, que envolvem } \\
\text { que iniciativas de incentivo à explicitação, documentação e disseminação do conhecimento. } \\
\text { Relevância d as capacitações desenvolvidas em treinamento s formais para desempenho das } \\
\text { funções na organização. }\end{array}$ \\
\hline Profissional 2 & $\begin{array}{l}\text { Enfase na codificação e retenção do conhecimento crítico para a organização. } \\
\text { Abordagem da relevância das comunidades de prática como forma de } \\
\text { aprendizagem organizacional e criar conhecimento. }\end{array}$ \\
\hline Profissional 3 & $\begin{array}{l}\text { Destaque para a importância da criação de competências de gestão, como forma de contribuir } \\
\text { para o gerenciamento efetivo do conhecimento através da gestão de pessoas. } \\
\text { Visualização do contexto organizacional de forma sistêmica, permitindo identificar os } \\
\text { elementos favoráveis à aprendizagem organizacional. }\end{array}$ \\
\hline Acadêmico 1 & $\begin{array}{l}\text { Relevância de assumir o pressuposto de que o conhecimento é um recurso organizacional, e a } \\
\text { cultura organizacional um dos determinantes para a aprendizagem organizacional. }\end{array}$ \\
\hline Acadêmico 2 & $\begin{array}{l}\text { Destaque para a exploração das inter-relações entre os elementos do framework utilizando como } \\
\text { referência conceitos e processos de criação e conversão do conhecimento, discutidos por } \\
\text { Nonaka e Takeuchi (1997), que abordam a criação de conhecimento na empresa propondo o } \\
\text { modelo do espiral do conhecimento. }\end{array}$ \\
\hline Acadêmico 3 & $\begin{array}{l}\text { Importância de estabelecer ligações que indiquem a relação causal e lógica entre os elementos } \\
\text { do framework, para entender com ma ior clareza o processo de aprendizagem organizacional e a } \\
\text { dinâmica da formação de competência durante o processo de aprendizagem organizacional. }\end{array}$ \\
\hline
\end{tabular}


FIGURA 4

Framework teórico-conceitual refinado

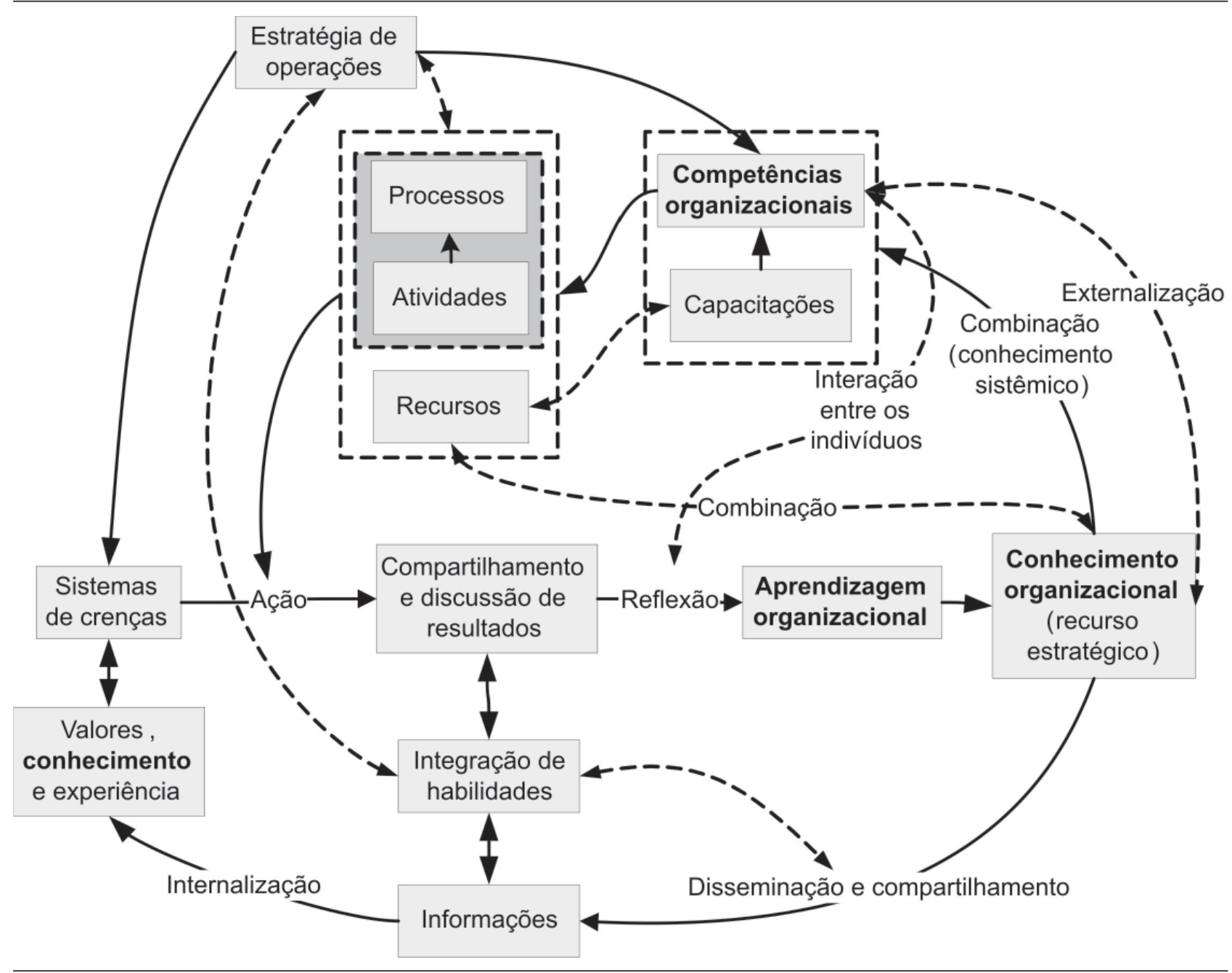

Fonte: elaborado pelos autores.

A figura 5, a seguir, apresenta o mapa cognitivo de um questionário respondido na DF.

Definida a metodologia de teste, podem ser discutidos os resultados.

\section{Resultados}

O quadro 6, a seguir, apresenta os elementos e as inter-relações identificadas no framework e nos mapas cognitivos resultantes da análise dos dados secundários, que evidenciam o vínculo entre a aprendizagem organizacional e a formação de competências organizacionais.

Ci. Inf., Brasília, DF, v. 38, n. 3, p.142-159, set./dez., 2009
Conforme se pode observar no quadro 6, existem ações e aspectos-chave presentes em mais de uma unidade organizacional, como os programas de capacitação formal desenvolvidos com base na gestão de competências, visando a suprir gaps de competências técnicas e gerenciais como forma de alinhar o desenvolvimento de competências à estratégia no nível das unidades ou diretorias e no nível corporativo.

O teste permitiu identificar elementos comuns entre o framework e os dados secundários analisados, que fazem parte do processo de aprendizagem e formação de competências organizacionais, tais como: 
FIGURA 5

\section{Mapa cognitivo da DF}

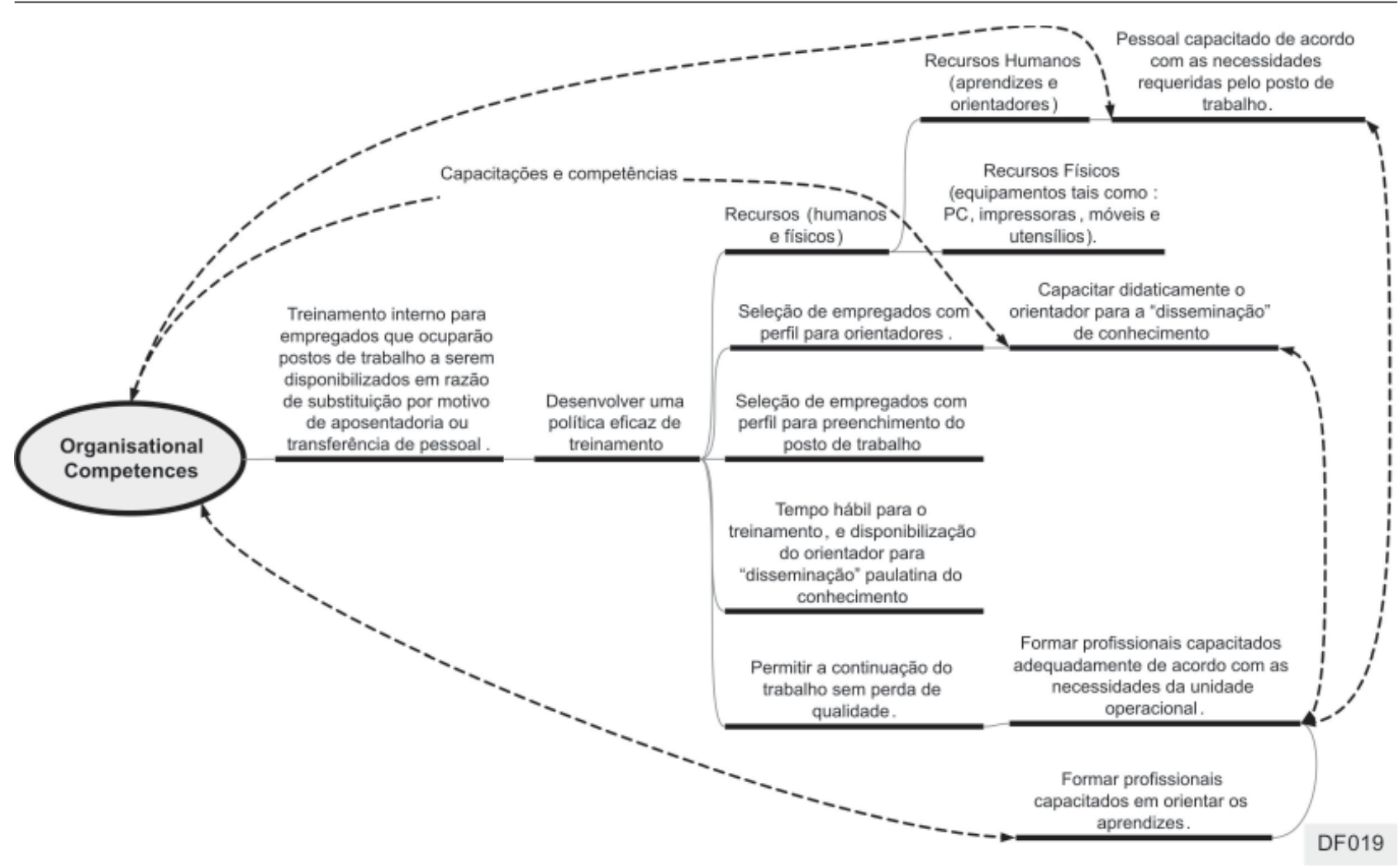

Fonte: elaborado pelos autores

- competências e capacitações organizacionais: mapeamento de competências para identificação de gaps entre os requisitos da função e as competências existentes, e para avaliação das competências existentes e não utilizadas, de modo a otimizar a alocação de recursos humanos nas áreas.

- aprendizagem organizacional: implantação de programas de educação corporativa estruturados para suprir os gaps de competências existentes e "utilizar" os conhecimentos dos especialistas que atuam na organização.

- conbecimento organizacional (recurso estratégico): foram identificadas ações relacionadas à retenção de conhecimentos técnicos estratégicos envolvendo processos e atividades de planejamento, programação e operação, e relativos à solução de problemas técnicos e gerenciais. Os programas de trainees na área técnica têm como um dos objetivos o compartilhamento e retenção do conhecimento dos especialistas mais experientes. Parcerias com universidades para pesquisa e desenvolvimento, visando à inovação e aprimoramento dos processos. - processos, atividades e recursos: mapeamento dos processos técnicos e de gestão relevantes para o alcance dos objetivos organizacionais e para a dinamização dos processos da unidade organizacional (visão sistêmica). A captação de recursos de conhecimento com a alocação de pessoas especializadas, com conhecimento técnico em tecnologias de banco de dados e estrutura de tecnologia da informação e comunicação.

- disseminação e compartilhamento de informações e conbecimento: gestão da informação, através de ambientes computacionais colaborativos para aprendizagem e armazenamento de informações estratégicas. Captura, organização, classificação, sistematização, manutenção, atualização e disponibilização de dados e informações técnicas e gerenciais estratégicos para a organização.

Ci. Inf., Brasília, DF, v. 38, n. 3, p.142-159, set./dez., 2009 
QUADRO 6

Variáveis e inter-relações identificadas no teste do framework

\begin{tabular}{|c|c|}
\hline $\begin{array}{l}\text { Variáveis e inter- } \\
\text { relações com o } \\
\text { framework }\end{array}$ & Aspectos relacionados à aprendizagem identificados na análise dos dados \\
\hline \multirow{3}{*}{$\begin{array}{l}\text { Competências e } \\
\text { capacitações } \\
\text { organizacionais }\end{array}$} & $\begin{array}{l}\text { Divulgar as competências existentes nas unidades para as demais unidades da organização } \\
\text { (banco de talentos). }\end{array}$ \\
\hline & $\begin{array}{l}\text { Mapeamento de competências organizacionais e avaliação de competências existentes e } \\
\text { não utilizadas, identificação de gaps de competências. }\end{array}$ \\
\hline & $\begin{array}{l}\text { Identificação e alocação de pessoas na organização com competências em gestão da } \\
\text { informação / dinamização na administração de competências. }\end{array}$ \\
\hline \multirow{2}{*}{$\begin{array}{l}\text { Aprendizagem } \\
\text { organizacional }\end{array}$} & $\begin{array}{l}\text { Implantação de Programa de Educação Corporativa. Planos de capacitação estruturados } \\
\text { para suprir os gaps e desenvolver competências técnicas e gerenciais específicas. }\end{array}$ \\
\hline & $\begin{array}{l}\text { Aprendizagem contínua com base em domínio funcional, critérios de decisão, consciência } \\
\text { organizacional e comunicação com áreas e provedores. }\end{array}$ \\
\hline \multirow{4}{*}{$\begin{array}{l}\text { Conhecimento } \\
\text { organizacional } \\
\text { (recurso estratégico) }\end{array}$} & $\begin{array}{l}\text { Formação de competências em desenvolvimento de processos estratégicos para a unidade } \\
\text { e/ou a organização. }\end{array}$ \\
\hline & $\begin{array}{l}\text { Implantação da Gestão Estratégica de RH e alinhamento dos requisitos de compet ências } \\
\text { corporativas à estratégia da organização. }\end{array}$ \\
\hline & $\begin{array}{l}\text { Implantação da Gestão do Conhecimento organizacional. Retenção de conhecimentos } \\
\text { técnicos estratégicos envolvendo processos e atividades de planejamento, programação e } \\
\text { operação, e relativos à solução de pro blemas técnicos e gerenciais. }\end{array}$ \\
\hline & $\begin{array}{l}\text { Parcerias com universidades para desenvolvimento de pesquisas avaliadas por especialistas } \\
\text { da academia e da organização, e geração de conhecimento utilizável para a organização. }\end{array}$ \\
\hline \multirow{3}{*}{$\begin{array}{l}\text { Processos, } \\
\text { atividades e } \\
\text { recursos }\end{array}$} & $\begin{array}{l}\text { Mobilização e sensibilização dos gerentes para a necessidade de desenvolvimento das } \\
\text { competências individuais e entendimento do valor das competências para atingir os } \\
\text { objetivos organizacionais. }\end{array}$ \\
\hline & $\begin{array}{l}\text { Mapeamento dos processos técnicos e de gestão relevantes para o alcance dos objetivos } \\
\text { organizacionais }\end{array}$ \\
\hline & $\begin{array}{l}\text { Recursos humanos especializados com conhecimento técnico em tecnologias de banco de } \\
\text { dados, e estrutura de tecnologia da informação e comunicação. }\end{array}$ \\
\hline \multirow{4}{*}{$\begin{array}{l}\text { Disseminação e } \\
\text { compartilhamento } \\
\text { de informações e } \\
\text { conhecimento / } \\
\text { Compartilhamento } \\
\text { e discussão de } \\
\text { resultados / } \\
\text { Integração de } \\
\text { habilidades }\end{array}$} & $\begin{array}{l}\text { Gestão da informação, através de ambientes computacionais colaborativos para } \\
\text { aprendizagem e armazenamento de informações estratégicas. Formulação de políticas de } \\
\text { incentivo ao compartilhamento e disseminação de informações (conhecimento tácito das } \\
\text { pessoas). }\end{array}$ \\
\hline & $\begin{array}{l}\text { Incentivo à participação de funcionários detentores de conhecimentos -chave em } \\
\text { seminários, palestras, reuniões e debates. }\end{array}$ \\
\hline & $\begin{array}{l}\text { Ações de rotatividade de funções (job rotation) entre postos de trabalho. Designação de } \\
\text { profissionais seniores para capacitar funcionários iniciantes. }\end{array}$ \\
\hline & $\begin{array}{l}\text { Gestão de conhecimento técnico - Implantação e manutenção de processos integrados de } \\
\text { resolução de problemas técnicos. }\end{array}$ \\
\hline $\begin{array}{l}\text { Sistemas de crenças, } \\
\text { conhecimento, } \\
\text { experiência }\end{array}$ & $\begin{array}{l}\text { Apoio à realização de palestras, workshops, debates e outros eventos internos e/ou } \\
\text { externos. }\end{array}$ \\
\hline \multirow{2}{*}{$\begin{array}{l}\text { Estratégia de } \\
\text { operações }\end{array}$} & $\begin{array}{l}\text { Implantação de sistemas de gestão de desempenho para suporte à gestão de recursos } \\
\text { humanos }\end{array}$ \\
\hline & $\begin{array}{l}\text { Planos de sucessão estruturados para retenção do conhecimento técnico estratégico para a } \\
\text { organização. }\end{array}$ \\
\hline
\end{tabular}


- estratégia de operações: fazem parte da estratégia de operações da instituição a implantação de sistemas de gestão de desempenho, de forma integrada e como suporte à gestão de recursos humanos; e os planos de sucessão estruturados para retenção do conhecimento técnico estratégico para a organização, a exemplo dos programas de trainees.

A aprendizagem organizacional requer iniciativas de compartilhamento e disseminação do conhecimento crítico para a organização, envolvendo elementos como:

- entendimento e desenvolvimento da visão baseada em recursos e seu papel na estratégia de operações;

- desenvolvimento da visão de manufatura, de modo a traçar uma ligação entre missão, objetivos e estratégia da organização;

- comprometimento de todos os níveis hierárquicos da organização sobre a importância do processo de aprendizagem para a geração de capacitações e competências organizacionais no âmbito da gestão de operações;

- identificação do conhecimento crítico ou estratégico para a organização que possa originar competências;

- conscientização e/ou capacitação dos detentores do conhecimento crítico, de modo que ele seja adequadamente explicitado;

- disseminação do conhecimento organizacional explicitado;

- comprometimento dos indivíduos e grupos com a internalização do conhecimento explícito crítico;

- construção de redes de aprendizado entre os indivíduos e grupos, onde possam ser compartilhadas ideias e experiências.

O framework teórico-conceitual desenvolvido é considerado aplicável para a metodologia utilizada e o teste realizado. $O$ teste possibilitou verificar que parte significativa das variáveis presentes nas informações geradas e nas inter-relações analisadas também estava presente no framework teórico conceitual.

Entretanto, é destacada a importância de maior aprofundamento e ampliação do escopo da pesquisa, para identificar, explicar e inter-relacionar as demais variáveis envolvidas.

\section{CONCLUSÃO}

A relevância das competências organizacionais para a mobilização dos recursos e o atingimento dos objetivos estratégicos da organização é consenso entre os autores, o que remete ao conceito das capacitações dinâmicas que é a capacidade da organização em adaptar competências para a mudança. Assim, a competitividade das empresas está vinculada a identificar e desenvolver comportamentos que levam à construção de competências essenciais para melhoria contínua, e a gestão destas competências exige o entendimento básico dos comportamentos relativos à cultura organizacional, a visão sistêmica dos processos e particularmente ao processo de aprendizagem organizacional. O estudo estabeleceu interconexões entre o processo de aprendizagem organizacional e a formação e desenvolvimento de competências, identificou interfaces, no entanto, há necessidade de aprofundar a compreensão a respeito da integração dos recursos, capacitações e competências ao processo de aprendizagem organizacional.

As limitações ocorridas ao longo da pesquisa estão relacionadas a três pontos principais:

- método de análise dos dados: por tratar-se de uma pesquisa de natureza qualitativa, muitos conceitos e inter-relações são subjetivos e podem variar em função da interpretação;

- interpretação de termos técnicos e siglas: muitas respostas mencionavam termos e siglas técnicos específicos da unidade organizacional, demandando tempo para identificação e interpretação;

- respostas em campos inadequados: uma quantidade significativa de respostas foi inserida em campos inadequados do questionário, o

Ci. Inf., Brasília, DF, v. 38, n. 3, p.142-159, set./dez., 2009 
que demandou mais tempo para localização e interpretação.

As sugestões para trabalhos futuros giram em torno do aprofundamento e da ampliação do escopo da pesquisa. Para aprofundar a pesquisa, sugerem-se entrevistas com número maior de especialistas, a realização do teste do framework em estudos de caso múltiplos, a fim de investigar questões relativas à usabilidade, factibilidade e utilidade. Para ampliação do escopo da pesquisa, uma das possibilidades é a inclusão da investigação de elementos da cultura organizacional, que representam as barreiras e facilitadores da aprendizagem organizacional, incluindo aspectos de comportamento individual.

Os resultados da pesquisa contribuem para melhor compreensão do papel dos processos de aprendizagem e a sua relação com a formação e desenvolvimento de competências, particularmente no que se refere à criação de valor na forma de conhecimento. Tal processo é entendido no nível das operações que interconectam as diferentes áreas e funções de uma organização. Assim, a pesquisa contribui para a área de gestão de operações à medida que aplica teorias e modelos de aprendizagem e competências organizacionais.

Embora o refinamento e teste do framework tenham viabilizado a compreensão e representação do processo, é certo que, pelas próprias limitações da pesquisa, pode-se obter maior detalhamento com o aprofundamento em estudos de caso múltiplos, incluindo métodos de análise quantitativos como complemento à análise qualitativa; e da ampliação do escopo da pesquisa, inserindo elementos relativos à cultura organizacional e aspectos comportamentais.

Artigo submetido em 02/10/2008 e aceito em 07/10/2009.

Ci. Inf., Brasília, DF, v. 38, n. 3, p.142-159, set./dez., 2009

\section{REFERÊNCIAS}

ARGYRIS, Chris. Knowledge for action: a guide to overcoming barriers to organizational change. San Francisco: Jossey Bass, 1993.

; SCHÖN, Donald A. Organizational Learning II: theory, method and practice. Reading: Addison-Wesley, 1996.

AWUAH, Gabriel Baffour. A firm's competence development through its network of exchange relationships. Journal of Business and Industrial Marketing, v. 16, n. 7, p. 574-599, 2001.

AYAS, Karen. Integrating corporate learning with project management. International Journal of Production Economics, v. 51, n. 1 e 2, p. 59-67, 1997.

BARNEY, J. Firm resources and sustained competitive advantage. Journal of Management, v. 17, n. 1, p. 99-120, 1991.

BEMFICA, Juliana do Couto; BORGES, Mônica Erichsen Nassif. Aprendizagem organizacional e informação. Ciência da Informação, v. 28, n. 3, p. 233-240, 1999.

BERGHMAN, Liselore; MAT'THYSSENS, Paul; VANDENBEMPT, Koen. Building competences for new customer value creation: an exploratory study. Industrial Marketing Management, v. 35, n. 8, p. 961 973, 2006.

BOOG, Gustavo G. O desafio da competência: como enfrentar as dificuldades do presente e preparar sua empresa para o futuro. São Paulo: Best Seller, 1991.

BROWN, Steve; BLACKMON, Kate. Aligning manufacturing strategy and business-level competitive strategy in new competitive environments: the case for strategic resonance. Journal of Management Studies, v. 42, n. 4, p. 793-815, 2005.

CECEZ-KECMANOVIC, Dubravka. A sensemaking model of knowledge in organisations: a way of understanding knowledge management and the role of information technologies. Knowledge Management Research \& Practice, v. 2, n. 3, p. 155-168, 2004.

CHANDRA, Charu; KUMAR, Sameer. Enhancing manufacturing operations effectiveness through knowledge based design. Integrated Manufacturing Systems, v. 14, n. 3, p. 278-290, 2003.

CHEN, Guoquan. An organizational learning model based on western and Chinese management thoughts and practices. Management Decision, v. 43, n. 4, p. 479-500, 2005.

Le; MOHAMED, Sherif. Empirical study of interactions between knowledge management activities. Engineering, Construction and Architectural Management, v. 14, n. 3, p. 242-260, 2007.

Yu-fen; WU, Tsui-chih. An empirical analysis of core competence for high-tech firms and traditional manufacturers. Journal of Management Development, v. 26, n. 2, p. 159-168, 2007.

CHOI, B.; POON, S.K.; DAVIS, J.G. Effects of knowledge management strategy on organizational performance: a complementarity theory-based approach. Omega, v. 36, n. 2, p. 235-251, 2006. 
COLLIS, Jill; HUSSEY, Roger. Pesquisa em administração: um guia prático para alunos de graduação e pós-graduação. 2. ed. Porto Alegre: Bookman, 2005.

DAWSON, R. Knowledge capabilities as the focus of organizational development and strategy. Journal of Knowledge Management, v. 4, n. 4, p. 320-327, 2000.

DE TONI, A.; TONCHIA, S. New production models: a strategic view. International Journal of Production Research, v. 40, n. 18, p. 47214741, 2002.

DESOUZA, Kevin C.; AWAZU, Yukika. Engaging Tensions of Knowledge Management Control. Singapore Management Review, v. 28, n.1, p. 1-13, 2006.

DIXON, Nancy M. The Organizational Learning Cycle: how we can learn collectively. 2nd. Gower: Brookfield, 1999.

DREJER, Anders. Illustrating competence development. Measuring Business Excellence, v. 5, n. 3, p. 6-10, 2001.

Organizational learning and competence development. The Learning Organization, v. 7, n. 4, p. 206-220, 2000.

ENOKI, Cesar Hidetoshi. Gestão de processos de negócio: uma contribuição para a avaliação de soluções de business process management (BPM) sob a ótica da estratégia de operações. Dissertação (Mestrado) - Escola Politécnica da USP, Departamento de Engenharia de Produção, São Paulo, 2006.

FERNANDES, Bruno; MILLS, John; FLEURY, Maria Tereza. Resources that drive performance: an empirical investigation. International Journal of Productivity and Performance Management, v. 54, n. 5/6, p. 340-354, 2005.

FLEURY, Afonso C. C; FLEURY, Maria Tereza Leme. Estratégias competitivas e competências essenciais: perspectivas para a internacionalização da indústria no Brasil. Gestão e Produção, v. 10, n. 2, p.129-144, 2003.

Aprendizagem e inovação organizacional: as experiências de Japão, Coréia e Brasil. 2. ed. São Paulo: Atlas, 1997.

Estratégias empresariais e formação de competências: um quebracabeça caleidoscópio da indústria brasileira. 3. ed. São Paulo: Atlas, 2004.

FLIASTER, Alexander; SPIESS, Josef. Knowledge mobilization through social ties: the cost-benefit analysis. Schmalenbach Business Review, v. 60, n. 1, p 99-117, 2008.

GARVIN, David A. Building a Learning Organization. Harvard Business Review. p. 78-91, Jul./Ago, 1993.

GRANT, R.M. The Resource-Based Theory of Competitive Advantage: Implications for strategic formulation. California Management Review. v. 33, p.114-135, 1991.

GUPTA, J. N. D.; SHARMA, S. Creating Knowledge Based Organizations. London: Idea Group, 2004.
HALAWI, L.A.; MCCARTHY, R.V.; ARONSON, J.E. Knowledge management and the competitive strategy of the firm. The Learning Organization, v. 13, n. 4, p. 384-397, 2006.

HAMEL, Gary; PRAHALAD, C. K.. The core competence of the corporation. Harvard Business Review, v. 68, n. 3, p. 3-15, 1990.

HARI, Subashini; EGBU, Charles; KUMAR, Bimal. A knowledge capture awareness tool: An empirical study on small and medium enterprises in the construction industry. Engineering, Construction and Architectural Management, v. 12, n. 6, p. 533-567, 2005.

HAYES, R.; PISANO, G. Beyond world-class: the new manufacturing strategy. Harvard Business Review, p.77-86, Jan./Feb. 1994.

; WHEELWRIGHT, Steven C. Competing Through Manufacturing. Harvard Business Review, v. 63, p. 99-109. Jan./Fev. 1985.

HOOGERVORST, Jan A. P.; KOOPMAN, Paul L.; VAN DER FLIER, Henk. Human resource strategy for the new ICT-driven business context. The International Journal of Human Resource Management, v. 13, n.8, p. 1245-1265, 2002.

HUNTER, Judy. Improving organizational performance through the use of effective elements of organizational structure. International Journal of Health Care Quality Assurance Incorporating Leadership in Health Services, v. 15, n. 3, p. 12-21, 2002.

JOHANSEN, J.; RIIS, J. O. Developing a manufacturing vision. Production Planning \& Control, v. 14, n. 4, p. 327-337, Jun., 2003.

JUNG, J.; CHOI, I.; SONG, M. An integration architecture for knowledge management systems and business process management systems. Computers in Industry, v.58, n. 1, p. 21-34, 2007.

KONERS, Ursula; GOFFIN, Keith. Managers' perceptions of learning in new product development. International Journal of Operations \& Production Management, v. 27, n. 1, p. 49-68, 2007.

KYRO, Paula. Revising the concept and forms of benchmarking. Benchmarking: An International Journal, v. 10, n. 3, p. 210-225, 2003.

LEE, Kun Chang; LEE, Sangjae; KANG, In Won. KMPI: measuring knowledge management performance. Information \& Management, v. 42, n. 3, p. 469-482, 2005.

LEE, S. M.; HONG, S. An enterprise-wide knowledge management system infrastructure. Industrial Management \& Data Systems, v. 102, n. 1, p. 17-25, 2002.

LEWIS, Michael. Analysing organizational competence: implications for the management of operations. International Journal of Operations and Production Management, v. 23, n. 7, p. 731-756, 2003.

LUSTRI, Denise; MIURA, Irene; TAKAHASHI, Sérgio. Knowledge management model: practical application for competency development. The Learning Organization, v. 14, n. 2, p. 186-202, 2007.

MACPHERSON, Allan et al. Re-conceptualising learning spaces: developing capabilities in a high-tech small firm. Journal of Workplace Learning, v. 15, n. 6, p. 259-270, 2003.

Ci. Inf., Brasília, DF, v. 38, n. 3, p.142-159, set./dez., 2009 
MARSH, Sarah J.; STOCK, Gregory N. Creating Dynamic Capability: The Role of Intertemporal Integration, Knowledge Retention, and Interpretation. Journal of Product Innovation Management, v. 23, n. 5, p. 422-436, 2006.

MASLEN, Ron; PLATTS, Ken. Manufacturing vision and competitiveness. Integrated Manufacturing Systems. v. 8, n. 5, p. 313-322, 1997.

MERALI, Y. Individual and collective congruence in the knowledge management process. The Journal of Strategic Information Systems, v. 9, n. 2-3, p. 213-234, 2000.

MILLS, J.; PLATTS, K.; GREGORY, M. A framework for the design of manufacturing strategy processes: a contingency approach. International Journal of Operations \& Production Management, v. 5, n. 4, p. 17-49, 1995.

; BOURNE, Michael. Competence and resources architectures. International Journal of Operations \& Production Management, v. 23, n. 9, p. 977-994, 2003.

MILLS, John et al. Strategy and Performance: Competing through competences. Cambridge: Cambridge University, 2002.

MIRANDA, Silvânia. Como as necessidades de informação podem se relacionar com as competências informacionais. Ciência da Informação, v. 35, n. 3, p. 99-114, 2006.

MURRAY, Peter; DONEGAN, Kevin. Empirical linkages between firm competencies and organisational learning. The Learning Organization, v. 10, n. 1, p. 51-62, 2003.

NADLER, David; GERSTEIN, Marc S.; SHAW, Robert B. Arquitetura organizacio nal: a chave para a mudança empresarial. Rio de Janeiro: Campus, 1992.

NONAKA, I. The Knowledge-Creating Company. Harvard Business Review, v. 69, n. 6, p. 96-104, Nov./Dec. 1991.

NONAKA, I.; TAKEUCHI, H. Criação de conbecimento na empresa: como as empresas japonesas geram a dinâmica da inovação. Rio de Janeiro: Campus, 1997.

PAIVA, Ely Laureano; ROTH, Aleda V.; FENSTERSEIFER, Jaime Evaldo. Organizational knowledge and the manufacturing strategy process: A Resource-based view Analysis. Journal of Operations Management, v. 26, n. 1 , p. $115-132,2008$.

PISANO, Gary P.; TEECE, David J. How to capture value from innovation: shaping intellectual property and industry architecture. California Management Review, v. 50, n. 1, p. 278-296, 2007.

ROSE, Jeremy et al. Management competences, not tools and techniques: A grounded examination of software project management at WM-data. Information and Software Technology, v. 49, n. 6, p. 605-624, 2007.

SANCHEZ, Ron. Understanding competence-based management: identifying and managing five modes of competence. Journal of Business Research, v. 57, n. 5, p. 518-532, 2004.

Ci. Inf., Brasília, DF, v. 38, n. 3, p.142-159, set./dez., 2009
SENGE, Peter M. A quinta disciplina: arte e prática da organização de aprendizagem. 7. ed. São Paulo: Best Seller, 2000.

SILVA, Sergio Luis da. Informação e competitividade: a contextualização da gestão do conhecimento nos processos organizacionais. Ciência da Informação, v. 31, n. 2, p. 142-151, 2002.

SINGH, Sanjay Kumar. Role of emotional intelligence in organizational learning: an empirical study. Singapore Management Review, v. 29, n. 2, p. 55-74, 2007.

SLACK, Nigel; LEWIS, Michael; BATES, Hilary. The two worlds of operations management research and practice: can they meet, should they meet? International Journal of Operations and Production Management, v. 24, n. 4, p. 372-387, 2003.

SPANOS, Yiannis E.; PRASTACOS, Gregory. Understanding organizational capabilities: towards a conceptual framework. Journal of Knowledge Management, v. 8, n. 3, p. 31-43, 2004.

TEECE, D.; PISANO, G.; SHUEN, A. Dynamic capabilities and strategic management, Strategic Management Journal, v. 18, n. 7, p. 509-533, 1997.

TOMAÉL, Maria Inês; ALCARÁ, Adriana Rosecler; DI CHIARA, Ivone Guerreiro. Das redes sociais à inovação. Ciência da Informação, v. 34, n. 2, p.93-104, 2005.

TURNER, J. Rodney; KEEGAN, Anne. Mechanisms of governance in the project-based organization: roles of the broker and steward. European Management Journal, v.19, n. 3, p. 254-267, 2001.

VANHAVERBEKE, Wim; PEETERS, Nico. Embracing innovation as strategy: corporate venturing, competence building and corporate strategy making. Creativity and Innovation Management, v. 14, n. 3, p. 246-257, 2005.

VASCONCELOS, Flávio C. Da gestão do conhecimento à gestão da ignorância. Revista de Administração de Empresas, v. 41, n. 4, p. 98102, 200

WANG, Yonggui; LO, Hing-Po. Customer-focused performance and the dynamic model for competence building and leveraging: a resource-based view. Journal of Management Development, v. 22, n. 6, p. 483-526, 2003.

YANG, Bai-Chuan et al.; On establishing the core competency identifying model: a value-activity and process oriented approach. Industrial Management \& Data Systems, v. 106, n. 1, p. 60-80, 2006.

YEO, Roland. The tangibles and intangibles of organizational performance. Team Performance Management: An International Journal, v. 9, n. 7/8, p. 199-204, 2003.

ZEHIR, C.; ACAR, A. Z.; TANRIVERDI, H. Identifying organizational capabilities as predictors of growth and business performance. The Business Review, v. 5, n. 2. p. 109-116, 2006. 